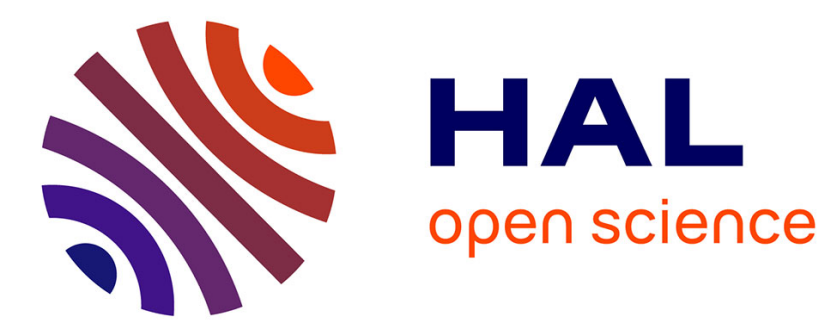

\title{
Making the history of computing. The history of computing in the history of technology and the history of mathematics.
}

Liesbeth de Mol, Maarten Bullynck

\section{To cite this version:}

Liesbeth de Mol, Maarten Bullynck. Making the history of computing. The history of computing in the history of technology and the history of mathematics.. Revue de Synthèse, 2018. hal-01814822

\section{HAL Id: hal-01814822 \\ https://hal.univ-lille.fr/hal-01814822}

Submitted on 13 Jun 2018

HAL is a multi-disciplinary open access archive for the deposit and dissemination of scientific research documents, whether they are published or not. The documents may come from teaching and research institutions in France or abroad, or from public or private research centers.
L'archive ouverte pluridisciplinaire HAL, est destinée au dépôt et à la diffusion de documents scientifiques de niveau recherche, publiés ou non, émanant des établissements d'enseignement et de recherche français ou étrangers, des laboratoires publics ou privés. 


\title{
MAKING THE HISTORY OF COMPUTING. THE HISTORY OF COMPUTING IN THE HISTORY OF TECHNOLOGY AND THE HISTORY OF MATHEMATICS
}

\author{
Liesbeth De Mol ${ }^{*} \&$ MaArten BullyncK ${ }^{* *}$
}

\begin{abstract}
AвstRact : A history of writing the history of computing is presented in its relationship to the history of mathematics. As with many historiographies, the initial history of computing was very much an internalistic history. In the late 1970s, the field became more serious and started looking at the histories of mathematics and technology for (methodological) inspiration. Whereas the history of mathematics was initially quite influential, it is the history of technology (in its U.S. form) that has become the dominant framework for doing history of computing since the 1990s.
\end{abstract}

KEYwORDs : Historiography of computing ; History of mathematics ; History of technology ; History of disciplines

The history of computing is a relatively young discipline, that formed slowly since the 1970s at a time when the discipline of computing itself was hardly established yet. It need not surprise that in its beginnings, the history of computing looked towards other historiographies for inspiration, for formats and methods for conserving and writing their histories. In the early days, it was influenced most by the history of technology and the history of mathematics.

While the history of computing is still closely allied with U.S. history of technology today (see section 4), its relationship with the history of mathematics or history of science in general has evolved over time and become distant, not directly contributing to its disciplinarisation. Instead sociology, business history, gender studies and other disciplines have been integrated into the philosophy and methodology of computing historiography following methodological developments of the Society for the History of Technology (SHOT

\footnotetext{
${ }^{*}$ Liesbeth De Mol (*1977) studied archeology, art history and philosophy in Gent and defended her PhD Tracing unsolvability: a mathematical, historical and philosophical analysis with a special focus on tag systems in 2007. Since 2013 she is a CNRS researcher at Université de Lille. Her work focuses on computability, early computer usages and the epistemological and historical connections between formalization and computer engineering. She is the founding president of the inter-divisionary DHST/DLMPST commission for the history and philosophy of computing (HaPoC). She is currently coordinating the ANR-funded research project PROGRAMme on the question " what is a computer program ? ».

${ }^{* *}$ Maarten Bullynck ( *1977) studied mathematics, German languages and media studies in Gent and Berlin. He defended his PhD Vom Zeitalter der formalen Wissenschaften. Parallele Anleitung zur Verarbeitung von Erkenntnissen anno 1800 in 2006. From 2007 to 2008 he was a fellow of the Alexander-von-Humboldt-Stiftung with a project on J. H. Lambert, including the development of a website featuring Lambert's collected works. Since 2009 he is maître de conferences at the Département de mathématiques et histoire des sciences at Université Paris 8. He publishes on the history of number theory, on the history of computing and on scientific communication in the $18^{\text {th }}$ century.
} 
for short). ${ }^{1}$ The aim of this paper is to offer a historical analysis of the history of the history of computing from the perspective of its relation with the history of mathematics,. We explain the distancing between the history of mathematics and computing by sketching their complex and at times strained relationship. ${ }^{2}$

\section{HISTORY OF COMPUTING GETS ON ITS FEET}

It is a typical phenomenon, in the process of a discipline becoming established, that its actors start to reflect on the past and take the initiative to write their own history. This is also true of the history of computing. Indeed, with the computer coming of age and in particular with the establishment of computer science and/or computer engineering departements in the United States. and the industrialized world during the 1970s, one sees also the first initiatives towards documenting, preserving and writing a history of computing. ${ }^{3}$ Part of this was supported by organisations and institutions such as the Smithsonian that started an oral history project on computing in the late $1960 \mathrm{~s}^{4}$, or the professional association AFIPS (American Federation for Information Processing Societies) that encouraged historical reflection including so-called Pioneer Days in their bi-yearly conferences. ${ }^{5}$ Computer companies also played an important part in financing some of the events. Another part was done by actors who started writing up their stories or even tried their hand at a more general, larger history.

An important event, especially for the larger public, was the big IBM exhibition A Computer Perspective, curated by the Eames's. It ran from 1971 to 1975 and attracted hundreds of thousands of visitors. It was documented by a lusciously illustrated catalogue offering a tour of the computer's history and prehistory. ${ }^{6}$ Together with two other, contemporary works, the Eames's catalogue provided the first book-length introduction to computing history. The other books were, first, H. H. Goldstine's personal account of the history of the computer, The Computer from Pascal to von Neumann (1972), featuring John von Neumann as a central figure, and second, Brian Randell's collection of primary sources, The Origin of Digital Computers (1973). ${ }^{7}$ Both books went through subsequent editions and became classic references to the field. ${ }^{8}$

1 It should be remarked that this evolution does not hold true for the history of computing outside the U.S., e.g. in many European countries the history of computing is written by historians of science or of mathematics. In much the same way, the separate ways of history of science and of technology described infra is a U.S. phenomenon that is not replicated in other countries, though its impact may be felt.

2 The authors would like to thank William Aspray, Martin Campbell-Kelly, Edgar Daylight,Thomas Haigh, David Nofre, Mark Priestley and Matti Tedre for their useful comments.

3 See also HAIGH, 2004 for an overview of early history of computing, and HaIGH, 2011a, for a more recent update going until 2010.

4 The Computer Oral History Collection (1969-1973, 1977), was a cooperative project of the American Federation of Information Processing Societies (AFIPS) and the Smithsonian Institution. This project began in 1967 with the main objective to collect, document, house, and make available for research source material surrounding the development of the computer.

5 See also Tropp, 1980.

6 EAMES \& EAMES, 1973.

Goldstine, 1972 ; Randell, 1973.

8 It should be pointed out that especially Goldstine's book is today considered to be a source that needs to be treated with great care, given the personal involvement of Goldstine with the history he is describing. 
In the second half of the 1970s, possibly profiting from a wave of public interest in computing, as witnessed by the many popular publications on the microcomputer (now: personal computer), a consolidation and institutionalisation started. Firms and institutions started to back more enduring forms of doing history. A landmark event was the International Research Conference on the History of Computing at Los Alamos (June 10-15, 1976) which resulted in the most important early edited volume on the history of computing. ${ }^{9}$ Amongst papers by various pioneers describing the machines and projects of the 1940s and 1950s, the book also included Donald Knuth and L.T. Pardo's long paper on the "Early Development of Programming Languages". ${ }^{10}$ This was one of the first more scholarly papers on the history of programming, together with Martin Campbell-Kelly's work on programming the early British computers (1979-1980). ${ }^{11}$

By the end of the 1970s, the Association for Computing Machinery (ACM) occasionnally began to organise focused sessions on the history of computing such as on the history of programming languages $(1977)^{12}$ or on the history of workstations (1986). Also, the American Federation for Information Processing Societies (AFIPS) continued its involvement. In 1979 it became a sponsor of the International Charles Babbage Society, founded 1978 by Erwin Tomash and associates. It was renamed the Charles Babbage Institute (CBI). The institute started an important oral history project, interviewing many historical actors, and built a big collection of books and documents. It remains an important center of documentation and scholarship in the history of computing until today. AFIPS also shouldered the creation of the specialized journal, IEEE Annals of the History of Computing, under the editorship of Bernie Galler, a computer pioneer who had done, amongst others, major work in timesharing. At first, the Annals published mostly actors' papers and recollections, but as history of computing become more professional, it has evolved into a journal that mainly publishes scholarly work. Today, Annals still are the main venue to publish in the history of computing.

Finally, Ken Olson and Gordon and Gwenn Bell, of the computer company Digital Equipment Company (DEC), founded the Digital Computer Museum in 1980 and started publishing some works on computer history through their Digital Press. ${ }^{13}$

The main driving forces of these initial years were institutions, organisations, companies and some prominent personalities from the field itself. They helped to create the first big collections, archives and publications for the history of computing. But it also implied that most of this early work was a rather internalistic, if not often whiggish, kind of history. They mostly focussed on the machines, or on important projects and persons, but generally did not go beyond the immediate historical context. Discussion of the broader sociohistorical background or the longer technological and scientific evolution was mostly absent.

\section{THE HISTORY OF COMPUTING WITHIN THE HISTORY OF MATHEMATICS}

As is clear from the previous section, the history of computing was first of all an initiative from within the computing field itself. Few professionally trained historians were

\footnotetext{
Metropolis \& Rota, 1980.

10 KNUTH \& PARDO, 1976.

11 Campbell-Kelly, 1980.

12 Wexelblatt, 1981.

13 The influence of DEC on the history of computing, not only material but also conceptual, would be an interesting story in itself, but falls outside the bounds of this article.
} 
involved. This initiative from several computing pioneers and institutions should certainly be seen against the background of the field's struggle for disciplinary independence. Indeed, it is only in 1962 that the first study program in "computer science" was launched at Purdue University. By the 1970s the discipline had become more established with a large number of established journals and conferences, graduate programs and $\mathrm{PhDs}$ in computer science but it was still struggling. Amongst others, in funding agencies, computing was still frequently grouped with mathematics.${ }^{14}$ It is against this background that one can detect a number of particular viewpoints, agendas and philosophies on what the discipline actually is (about). One dominant viewpoint in the 1960s and 1970s was the idea that computing is in fact mathematics. ${ }^{15}$ It is no surprise that this viewpoint also colours some of the most prominent historical works from the 1970s, trying to embed the history of computing into the history of mathematics.

H. H. Goldstine was trained as a mathematician before he became an officier in the U. S. military and got involved with one of the first computers, ENIAC. In his book on the history of the computer, he emphasized the mathematical pedigree of the computer, and highlighted his colleague John von Neumann's rôle in the creation of the modern digital computer. In a completely different way, the Stanford computer scientist Donald E. Knuth's early writings on computing history also focused on the mathematical aspect of computing, but this time to advance his agenda of founding "computer science" as the science of algorithms. Both authors tried their hands at the historiography of computing using an older and respected tradition in the history of mathematics, viz. the history of mathematics as practised in Göttingen just before the $2^{\text {nd }}$ World War. This vision on the history of mathematics was voiced most influentially by Otto Neugebauer, specialist of Babylonian mathematics. He stood for an internalist, mathematical history of ideas embedded in an acribic, even philological model of editing and commenting (ancient) mathematical sources.$^{16}$ When Neugebauer, as many other German mathematicians, emigrated in the 1930s to the United States, he continued to teach his historiographic vision there too.

In his book on the computer (and later in his History of numerical analysis (1977)) Goldstine placed the history of the computer in the lineage of the history of mathematics. In both books, he explicitly thanked Otto Neugebauer for his advice. In the part on computing before World War II, it is mostly mathematicians (Pascal, Boole, etc.) and mathematical problems (Fourier analysis, ballistics etc.) that make up the story, and with the focus on John von Neumann this co-evolution of mathematics and the computer reaches its apogee.

Donald. E Knuth's paper “Ancient Babylonian algorithms”, written for the 1972 anniversary issue of the Communications of the ACM, used Babylonian mathematics to construct an intellectual prehistory for programmers. ${ }^{17}$ To do this, he relied on Neugebauer's edition and interpretation of Babylonian mathematical texts. Tying together a long-term history of doing mathematics from the Babylonians to the digital computer, insisting on how difficult it is to properly formalize a computation, served Knuth's goal to legitimize his science of algorithms. Knuth also included copious historical notes and references in his 3volume The Art of Computer Programming (1968, 1969, and 1973) and has published a

\footnotetext{
14 TEDRE, 2015.

15 Matti Tedre gives an in-depth analysis of the disciplinary formation of computing and concludes that even today there is no consensus about the field's identity. Based on Tedre's work, one can identify four main positions, viz. computing as engineering, computing as mathematics, computing as a science and computing as an entirely new kind of interdisciplinary discipline.

16 Rowe, 2016.

17 KNUTH, 1972.
} 
number of historical articles on programming concepts (compilers, programming langages etc.) that remain standard references for people in computer science.

The emulation of a technically oriented, internalistic approach to history as practiced in the Göttingen environment, is by no means a coincidence. Because of the prestige Göttingen carried for the U.S.'s intellectual elite, its invocation by a young historiography of computing helped to legitimize itself, though by then, the history of mathematics was already on a new path, away from an internalistic and purely technical historiography (see Sec. 3).

This respectful reverence to a technically oriented, internalistic approach to history that meticulously edits and comments its sources, as practiced in the Göttingen environment, is by no means a coincidence, but rather served as a prestiguous example for the young historiography of computing.

The historical foundation of the field of computing into the history of mathematics is pursued by the chairs of the important International Research Conference on the History of Computing at Los Alamos (June 10-15, 1976). In the foreword to the proceedings of that conference, the so-called "computer revolution" is historically rooted into early $20^{\text {th }}$ century developments in mathematical logic, with reference to Turing, Church, Peano and Russel and Whitehead, and it is claimed that:

"The improbable symbolism of Peano, Russel, and Whitehead, the analysis of proofs by flowcharts spearheaded by Gentzen, the definition of computability by Church and Turing, all inventions motivated by the purest of mathematics, mark the beginning of the computer revolution. Once more, we find a confirmation of the sentence Leonardo jotted despondently on one of those rambling sheets where he confided his innermost thoughts : " Theory is the captain, and application the soldier." ${ }^{18}$

At that same conference, two researchers were asked to give a more reflective talk on the historiography of computing. The first was by Hamming, a mathematician turned computing pioneer who received the Turing award in 1968, with a talk titled "We would know what they thought when they did it". ${ }^{19}$ In the talk he developed the idea that the history of computing should not be a mere recollection of "firsts, names, places, dates, numbers, speeds, etc." but rather study the "creation, development and spread of ideas" and argued for the significance of a history which is not just written by (and for) historians who do not know much of computer science nor by computer scientists who do not know much of historical methods. Moreover, he invited historians to go beyond the documents to "informed speculation" about what the computer pioneers thought and did.

The second talk was by Kenneth O. May, a renowned historian of mathematics, founding chair of the International Commission for the History of Mathematics ${ }^{20}$ and cofounder of the journal Historia Mathematica. May belonged to a new generation of historians of science who was "squared of Sarton".$^{21}$ Sarton was the founder of the well-known Isis journal for the history of science and promoted a view on the history of science that fitted his so-called New Humanism and which required that historical work should be done

18 Metropolis, Howlett \& Rota, 1980, p. xvi.

19 Hamming, 1980, quotes from p.9 and 6.

20 Initially the commission was a subcommittee of the DHS (which later became DHST - Division for the History of Science and Technology). In 1985 it became an inter-unary commission of the ICSU unions International Mathematical Union and the International Union of the History and Philosophy of Science.

21 MAY, 1974, p. 127. 
collaboratively by historians and scientists. ${ }^{22}$ The objective then is to unveil the hidden history of science which is, ultimately, rooted in mathematics which thus becomes a "secret within a secret”. ${ }^{23}$ May derived exactly this philosophy from Sarton in his plea for heterogeneity in the history of mathematics and the need for generalists "who can be mathematicians, historians of science and historians at the same time". ${ }^{24}$

In his talk at the Los Alamos conference titled "Historiography : A perspective for computer scientists", May insisted on integrating the computer in the history of mathematics, even introducing a "new" tradition in mathematics. Next to "mathematical science", May has also "mathematical technology" which includes numeration, calculating devices (on the hardware side) and algorithmic traditions (on the software side) :

"If we look at the history of mathematics this way, it seems to me that one of the effects of the coming of the electronic computer is that for the first time mathematical technology has become a consciously recognized discipline [...] instead of just being for practitioners who didn't seem to be in the mainstream, computing now becomes the Queen of Technology.”25

May's remarks go into two directions, attracting the history of computer science in the realm of the history of mathematics (which did not work out), but also enlarging the focus of historians of mathematics to mathematical technology and computing (which did happen). Indeed, the advent of the digital computer had an impact on the historiography of mathematics where a number of researchers began to actively study computing and algorithms in their own right. ${ }^{26}$

\section{CRISIS IN THE HISTORY OF MATHEMATICS AND ITS IMPLICATIONS FOR THE HISTORY OF COMPUTING: HOW M.S. MAHONEY TURNED TO THE HISTORY OF COMPUTING}

The mid 1970s was an important transition period for the historiography of mathematics. History of mathematics had slowly emancipated itself from being a marginal occupation of mathematicians to become an academic discipline for itself. It is also from that context of a more professional history of mathematics that May makes his plea for a heterogenuous history of mathematics. It is the growth in number and quality of historians of science which is :

"creating an employment crisis in a context of shrinking budgets, in spite of the continuing relative strength of the discipline. Many young scholars are getting along with makeshift arrangements, and some may leave the field [...] If we recognize the need for heterogeneity in training and approach [...] and if we agressively take advantage of employment opportunities in all areas [...] the present employment crisis could be

22 See for instance SarTon, 1924.

${ }^{23}$ Here is the full citation: "If the history of science is a secret history, then the history of mathematics is doubly secret, a secret within a secret, for the growth of mathematics is unknown not only to the general public, but even to scientific workers.” (SARTON, 1936, p. 4)

24 MAY, 1974, p. 128.

25 MAY, 1980, p. 17.

26 KnUth, 1972 was quite influential here ; a seminal article was Chemla, 1987. See Bullynck, 2016 for a more complete overview and assessment. 
transformed into an opportunity for healthy development of a fourth and successive generations." 27

The new generation of historians turned their attention to the more practical and mundane aspects of mathematics as well as on reading ancient mathematical cultures not with the lenses of modern mathematics but as a discourse in its own right. The raised selfawareness of the discipline, however, also led to some fierce debates between historians and mathematicians. It basically came down to the question of whether the history of mathematics should be done by historians and/or by mathematicians.

This crisis in the historiography of mathematics was fought most virulently over the interpretation of Babylonian and Greek mathematics, notably in the so-called Unguru debate. ${ }^{28}$ In 1975 Sabbetai Unguru published a paper in the Archive for the history of exact sciences where he argued that Greek (or Babylonian) mathematics is not algebra, and should thus not be put in modern mathematical terms, but has to be considered as a discourse in its own. In the process, Unguru referred to a 1971-paper by Princeton-based Michael S. Mahoney that suggested that you can only speak about algebra from the $17^{\text {th }}$ century onwards. ${ }^{29}$ Unguru's paper resulted into a controversy during which a number of famous mathematicians would send angry letters to the editors of the Archive. These mathematicians included the Bourbaki mathematician André Weil ${ }^{30}$ and B.L. van der Waerden, both of which wrote some important work on the history of mathematics. This discussion, symptomatic of the growing divide between mathematicians and historians vis à vis history of mathematics, eventually led to a greater intellectual independence of the historians from mathematicians and to the slow recognition of the history of mathematics as a specialisation in its own right, though part of the tensions between mathematicians and historians would remain unresolved until today.

One of the historians of mathematics that became tied up into these disputes eventually became the inhouse historian for the first generation of (mostly U. S .) historians of computing. Michael S. Mahoney had published a book on the career of Pierre de Fermat in 1973 probably as part of getting tenure as a professor at Princeton. The book was met with one of the most scathing reviews ever written. The review's author was Weil who was also at Princeton around the time. Weil found Mahoney's book lacking in knowledge of mathematics, of French, of Latin but also in history and context, and detailed over 12 pages many misinterpretations and errors he found in the book. Weil wrote that "a student of $17^{\text {th }}$ century mathematics will find little in that volume that could be helpful to him, and much that can only confuse and mislead him." ${ }^{31}$ Though Weil's criticisms were, in part, correct $^{32}$, their general tenet has to be seen in the light of the contemporary debates between historians and mathematicians.

According to William Aspray, Weil's review had a lasting impact on Mahoney's research direction and output and eventually helped him to get involved with the history of computing

27 MAY, 1974, p. 128.

28 For more on the context of the debate around Unguru, see SCHNEIDER, 2016.

29 Mahoney, 1971.

30 Weil,would publish an important book on number theory using history, Number theory: An approach through history from Hammurapi to Legendre, doing the exact opposite, reading and interpreting history with the newest developments in mathematics at the horizon.

31 WeIL, 1973, p. 1149.

32 Compare with Itard's review (ITARD, 1974), who is equally critical of the book, but less polemical in his remarks. 
some ten years later. ${ }^{33}$ After Weil's rip-up of his book, Mahoney shied away from writing on the history of mathematics proper, and concentrated mainly on his teaching. Through his teaching at Princeton, and its vicinity to some of the important sites of computing such as Bell Labs, Mahoney got gradually more involved in the history of computing. This involvement spread to his research in the late 1980s. In 1987, Mahoney was asked to become editor of the ACM History Series and in 1988 he published the article "The History of Computing in the History of Technology", which became one of the most quoted papers ever to appear in the IEEE Annals for the History of Computing. ${ }^{34}$

His work in the history of computing ranges from developments in theoretical computer science to social aspects of developments in software engineering but he his mostly known in the community for his more methodological viewpoints on how the history of computing should be conducted and what its topics should be. Although Mahoney started to publish about computing after a first generation of professional historians had already started their work in the early $1980 \mathrm{~s}^{35}$ the impact of his work on the community of historians of computing should not be underestimated. Even today, he is still regarded by many as the most important and influential historian of computing. ${ }^{36}$ Thomas Haigh, who is one of the most active and appreciated historians of computing of today, describes the impact of his methodological work as follows:

"Mahoney's most influential contribution to the development of the history of computing as a thriving and somewhat respectable field of scholarly labor came from his series of historiographic papers published from 1988 to 2008. [...] These papers constitute the most sustained and self-conscious examination so far attempted of the fundamental question hanging over our growing body of work: what is the history of computing a history of?”37

His methodological work was considered so important that one of Mahoney's short methodological papers titled "What makes history?" was "used as a primary reference for prospective authors to the Annals for several years". ${ }^{38}$ That same paper was also added as an Appendix to the proceedings of the second conference on the History of Programming Languages which was basically modeled after the Los Alamos conference from 1976 and for which Mahoney was the so-called "conference historian". That paper goes back to Hamming's paper, discussed in Section.2, and offers some "advices" to the computer scientist who wants to write and reflect on his/her own history. Amongst others he warned exactly against what was considered to be the main issue within the previously mentioned Unguru debate and what is known as whiggism: to reread history through our contemporary perspective.

But it is worthwhile to go back to Mahoney's first written contribution to the field. Its basic methodological viewpoint is summarized in the paper's title "The history of computing in the history of technology". He situates computing at the nexus of science and technology, taking up contemporary discussions on the history of science and technology in the United States:

\footnotetext{
33 Aspray, 2014, p. 73 and footnote 17.

34 Mahoney, 1988.

35 Such as I. Bernard Cohen, Martin Campbell-Kelly, Paul Ceruzzi, Nancy Stern or William Aspray.

36 A more measured assessment of Mahoneys work can be found in Martin Campbelly-Kelly's review (CAmpbell-Kelly, 2013) who points out that Mahoney's prestige as a Princeton professor played an important rôle in his influence.

37 HaIGH, 2011b, p. 2.

38 LeE, 1996, about Mahoney, 1996.
} 
"Between the mathematics that makes the device theoretically possible and the electronics that makes it practically feasible lies the programming that makes it intellectually, economically, and socially useful. Unlike the extremes, the middle remains a craft, technical rather than technological, mathematical only in appearance. It poses the question of the relation of science and technology in a very special form."39

To Mahoney, to get away from a machine and person centered history written by those who lived it, a turn towards the history of software and of computing systems would connect directly to many of the then current issues in the history of technology, such as the interaction between industry, business, society and technology. According to Mahoney, the computer has a tripartite nature: computer science, electrical engineering, and programming/software engineering. While the first two aspects might fall under the more classical histories of science and technology respectively, the proper home of the history of computing as a new field would be within the larger history of technology as it was developing in the U.S. in the 1980s:

"What is truly revolutionary about the computer will become clear only when computing acquires a proper history. [...] Pursued within the larger enterprise of the history of technology, the history of computing will acquire the context of place and time that gives history meaning." ${ }^{40}$

Through his involvement in the ACM, in the Annals and his scholarly articles Mahoney helped shape the field and set an agenda for the younger generation of researchers, focusing more on the social aspects of computing, taking on software and moving to business history. He was also important in keeping contact with leading computer scientists and getting them to write historical contributions. He was an important motor in this change of research direction, away from the history of science (and of mathematics in particular), towards more sociological, institutional and economical histories of computing. Paradoxically though, he devoted most of his output in the history of computing to one of the most mathematical aspects of computing, viz. the development of theoretical computer science and the research into mathematical theories and structures of computation. ${ }^{41}$

\section{HISTORY OF COMPUTING IN THE HISTORY OF TECHNOLOGY}

Ironically then, it was thus a historian of mathematics who, together with many others, led the way to the steady dissociation of the history of computing from the history of mathematics and science proper and helped paved the way to its integration into the U. S. history of technology. While Mahoney himself certainly remained engaged as much with the history of science as with the history of technology, the effect of inscribing the history of computing into the history of technology, has affected the field fundamentally.Also Martin Campbell-Kelly, another pioneer historian of computing, advocated such a turn away from history of science: "In fact, I would argue [...] that the history of computing is a special case, and not really like the history of mathematics or physics at all. Computing is the dominant technology of the second half of the twentieth century, which pervades all aspects of

\footnotetext{
39 Mahoney, 1988, p.117.

40 Mahoney, 1988, p.123.

41 See Mahoney, 2011, part 3.
} 
economic life. In this, it is more akin to business history.” (Campbell-Kelly in Rosin, 1993, p. 804) ${ }^{42}$

This turn away from the history of science reflects, with a delay, the evolution of the field itself. While scientific computing was a very important catalysator in the early history of computing (the 1940s and 1950s), other forms of computing became increasingly important later. From the 1950s onwards business computing and data processing became more and more important. Later still, (tele)communications, realtime systems and networking also became important areas for computing. As a consequence, the field itself had to diversify its methodologies and, in the meantime, try to keep up with the new demands from the application-side. Whereas, to this day, several computer scientists remain convinced of the need for a mathematical foundation of the computing field, including the engineering of software, it is clear that the reality requires a more diversified approach which does not reduce to one or the other field. This broadening and deepening of the field of computing slowly had an impact on the history of computing. Its original contact with history of science and of mathematics watered down, while its ties to history of technology, history of information processing and business history ${ }^{43}$ strengthened. In recent years especially, it has been suggested to inscribe the history of computing in a much broader history of information, ${ }^{44}$ which is perhaps again a reflection of the field's own self-perception as being the science of information processing. ${ }^{45}$

The trend away from the history of science towards the history of technology was reinforced by the constitution in 1987 of the Special Interest Group Computers, Information, Society, SIGCIS for short, that has currently evolved into the main community for historians of computing. ${ }^{46}$ SIGCIS was founded during the annual Society for the History of Technology (SHOT) convention, and remains, until today, embedded in that society with, amongst others, the annual SIGCIS workshop held during the annual SHOT conference.

SHOT was founded in the United States in 1958. The the main motivation for the creation of SHOT was the impression that historians of science did not take history of technology seriously enough, an impression that was strengthened by the refusal of the reputed Isis, journal of the History of Science Society to devote more space to papers on the history of techology. SHOT consequently started its own journal Technology and Culture. This tension, if not divide, between the history of science and the history of technology remains very much alive. SHOT still suffers from a "self-perception of marginality", and is "a tightly knit organization, and, among its members, the distinction between outsiders and insiders remains highly salient". ${ }^{47}$ One of the most debated issues, it need not wonder, was and is the difficult, strained relationship between science and technology. The quite recent debate around a paper by Paul Forman (2007), who argued that the traditional, modernist primacy of science over technology has been reversed since the (postmodern) 1980s,

42 As many others around that time, Campbell-Kelly singles out James Beniger's book Control Revolution (1986) as showing "the vast canvas on which the history of computing will ultimately be painted".

43 For business history, especially the influence of Alfred D. Chandler Jr. was important.

44 Aspray, 1994 was one of the first to point out it might be useful to treat the history of computing, communications and broadcasting in the same framework. See Haigh, 2011a and Aspray, 2015 for more recent viewpoints on this issue.

45 See e.g. Denning 2009.

46 An overview of its history may be found at https://www.sigcis.org/about history. Remark that SIGCIS has both a Mahoney fund and a Mahoney prize, which is indicative of Mahoney's standing within that community.

47 Staudenmaier, 1990. 
illustrates amply how central and how controversial the issue remains. ${ }^{48}$

Embedding the history of computing in the history of technology thus also means that the SIGCIS community inherits from SHOT's history and many a historian of computing will go look for methods and viewpoints in the community of historians of technology. This has led U.S. historians of computing to adopt SHOT's emphasis on "storytelling" 49 sometimes to the detriment and ignorance of technical details, and to follow current opening of SHOT to narratives of class, race and gender. It has equally and often led to ignoring the history of science, especially when technical. ${ }^{50}$

Of course, the history of computing has not remained confined to SHOT and it has learnt much from other histories such as business history or communications history. From the 1990s onwards, history of computing has become less a predominantly anglosaxon field, to become a more diverse and international discipline, as witnessed by the publications in the Annals and by a steady volume of book publications on a variety of topics. A first generation that had a some training in history of computing proper started to publish and the discipline has become increasingly self aware within and outside of SHOT. ${ }^{51}$ Important landmarks were the first historian's textbooks on the computer's history: Martin Campbell-Kelly and William Aspray's Computer: A history of the information machine (1996), and Paul Ceruzzi's A history of modern computing (1998). ${ }^{52}$ Both books went through updated editions later on and still are standard reference works often used for teaching a class on the history of the computer. More recently, one sees that more attention has been going to the application side of computing. ${ }^{53}$ It is within that development that one can notice an increased interest for the use of computing technology and its effects on science. ${ }^{54}$ A number of national and international committees and musea were founded outside of the United States which also contributed to this process of internationalisation and diversification. ${ }^{55}$ This process of both methodological diversification

48 Forman, 2007.

49 For instance, on the website of SHOT in the section of "Doing history of Technology" one finds a quote from Usselman, a well-known historian of technology, saying that : "Historians of technology $[\ldots]$ are storytellers. More than any other practitioners among the humanities and social sciences, historians practice the art of narrative, and in doing so we face many of the same challenges as the fiction writer" (see: https://www.historyoftechnology.org/doing-history-oftechnology/, accessed May 22, 2018).

50 So, for instance, in his opinion piece “The tears of Donald Knuth” (HaIGH, 2015), Thomas Haigh sketches a development of the history of computing which should be non-technical (because written by and for historians). He concludes that a history of computing which engages more with the science of computing and which is written by professional historians also with an eye on a computer science public is "almost impossible to accomplish" (with the exception of Martin Campbell-Kelly). See Sec. 5 for more details.

51 Indeed, it is no accident that the SIGCIS workshop has evolved from a rather small event within SHOT to one of the events with the highest number of contributions. This growing self-awareness is witnessed by the fact that in 2016 SIGCIS held its first meeting which was not co-located with SHOT.

52 Campbell-Kelly \& Aspray, 1996; Ceruzzi, 1998.

53 Campbell-Kelly, 2007.

54 See for instance the work by Paul N. Edwards on climate science (EDwards, 2010) or the work by Joseph November on the computerization of biomedical research (NovEMBER, 2012).

55 Well-known examples are the Heinz Nixdorf museum in Paderborn or the Computer Conservation Society in the UK. In Switserland the Association Histoire et Informatique was founded in 1989. It focuses mostly but not exclusively on the use of the computer in historical research. In France there was a series of conferences on the history of computer science from the late 1980s until the early 2000s in which the French historian Pierre Mounier-Kuhn played a signficant rôle. In the 
(following SHOT in part) and internationalisation can also be observed when going through the list of recent winners of the Computer Museum Prize or the Mahoney Prize that honour important work in the history of computing. ${ }^{56}$

\title{
5. DONALD KNUTH'S TEARS - A CRISIS IN THE HISTORY OF COMPUTING?
}

In 2007 Martin Campbell-Kelly published an analysis of the evolution in the historiography of computing, "The history of the history of software". ${ }^{57}$ Central to the paper is a table in which he lists publications on the history of software starting in 1967 and ending in 2004. Each publication is assigned one of four classification types: T(echnology), S(upplyside industry), I(institutional,social, political) and A(pplications) and it is observed that whereas initially all papers are assigned the label $\mathrm{T}$, later on there are no more $\mathrm{T}$ publications to be found. This development is applauded by Campbell-Kelly, identifying the more

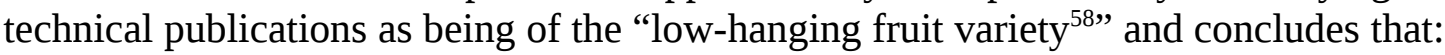

\begin{abstract}
"[T]he subject matter has broadened. In the 1960s and 1970s, people wrote about technology -- code and software engineering practices. Starting in the 1980s, people began to write about software as an economic activity. [...] In the 1990s, especially, we began to see books that set software in a much broader institutional, social, or political setting. [...] It is only in the past 10 years that scholars also began to look at applications. [...] Thus, over time, software history has evolved from narow technical studies, through supply-side and economic studies, to broad studies of applications." ${ }^{59}$
\end{abstract}

Initially the paper did not result in much debate. It was only when Donald Knuth, famous computer scientist and strong advocate of the history of computing, publicly expressed his feelings about the paper on several occasions, that the community of historians of computing started a serious discussion. During his Kailath lecture at Stanford University titled "Let's not dumb down the history of computing" (2014), Knuth explained that: "when I was reading [the] page [explaining the table] I broke down and started to cry and I finished reading it only with great difficulty because tears had made my glasses wet”. Addressing Campbell-Kelly in his talk Knuth said: ${ }^{60}$

"Do you not see any blind spots in your outlook when your table 1 shows $68 \%$ class T articles in the first 20 years and $0 \%$ class $\mathrm{T}$ in the last 5 years? And then you say the table

Netherlands Gerard Alberts brought together an important number of historians (European and nonEuropean) for a research project on ALGOL (cfr « Software in Europe »). More recently still, the International Commission for the History of Science and Technology (ICHST) and the Commission for Logic, Methodology and Philosophy of Science (CLMPS), both falling under ICSU (International Council for Science), approved the proposal to create an interdivision Commission for the History and Philosophy of Computing (www.hapoc.org).

56 See https://www.sigcis.org/chmprize for the Computer History Museum Prize (since 2009) and https://www.sigcis.org/mahoneyprize for the Mahoney Prize (since 2015). Also the recent literature overview in Haigh, 2011a surveys the diversity of the field.

57 Campbell-Kelly, 2007.

58 Ibid., p. 44.

59 Ibid., p. 43.

${ }^{60}$ The video of the talk is available here : http://kailathlecture.stanford.edu/2014KailathLecture.html Last accessed May 22, 2018. 
shows how the subject matter has broadened. It has not broadened it has totally shifted. All we get nowadays is dumbed down [...] Thank Goodness historians of mathematics have not [....] entirely abandonened writing articles that contain formulas or explain scientific ideas rather than just sticking to things like the strategies a mathematician has used to get into academy or something.[...] I'm sure that business histories are as difficult to write as technical histories and they are no doubt also as valuable to business man as technical histories are valuable to technicians. But you seem to be celebrating the fact that nobody writes technical CS history at all anymore. When you speak of obvious holes you are thinking of obvious holes in business history and you mention the video game industry for example [...] The lack of anything even close to describing these techniques [invented in the video game industry] and how they were discovered and under what constraints they were discovered seems to be a much more obvious hole but you show no indication even to admit its existence.”61

Knuth's talk was picked up by Thomas Haigh who initiated a vivid internal discussion on the SIGCIS mailing list. Haigh eventually published his take on the discussion in a Viewpoint written for the reputed computer science journal Communications of the ACM .

Knuth's talk was picked up by the SIGCIS mailing list and resulted in a vivid internal discussion. Thomas Haigh eventually summarized and analyzed the discussion in a Viewpoint written for the reputed computer science journal Communications of the ACM.

Haigh argued that there are currently two "disciplinary base camps " from which writing the history of computer science might be undertaken: computer science itself and history. Both approaches could be complementary, but to Haigh, combining both is " almost impossible to accomplish .» computer science itself and the history of computing. To Haigh, Knuth cannot expect historians of computing to write more technical histories of computer science since their social and academic context is one that does not appreciate this kind of writing. As a consequence, the job opportunities for the more technically oriented historian are quasi nihil and it is up to the computer science departments themselves to make possible the kind of history that Knuth wants. Thus, Haigh concludes :

"Work in the history of computing has been seen by most in the humanities as dull and provincial, excessively technical and devoid of big historical ideas [...] I share Knuth's regret that the technical history of computer science is greatly understudied. The main cause is that computer scientists have lost interest in preserving the intellectual heritage of their own discipline [...] More work by professionally trained historians on social, institutional, and cultural aspects of computing does not have to mean less work by computer scientists themselves. They cannot count on history departments to do this for them, and I hope Knuth's lament motivates a few to follow his lead in this area." ${ }^{62}$

This more recent discussion between computer scientists and historians is symptomatic. On the one hand, it echoes once more the historian of technology's sentiment of working at the margins (of humanities here), and on the other hand, their disinterest in the technical aspects that are left for the scientists themselves. It also shows that the practitioners of the field are no longer are the intended main audience for the largest community of historians of

61 KNUTH, 2014, transcription by the authors.

62 Haigh, 2015, p. 42-43. This viewpoint focuses mostly on the academic system in the U. S. and it is perhaps no accident that the scholars mentioned in Haigh's paper who work “[c]ontrary to Knuth's despair and to Campbell-Kelly's march of progress away from technical history”, are mostly nonU. S. scholars. 
computing, and that historiography has set its thematic and methodological preferences accordingly.

\section{DISCUSSION : A CHALLENGE FOR «THE » HISTORY OF COMPUTING}

It is perhaps no accident that Knuth quoted exactly the history of mathematics as a counter example to the evolution in history of computing he deplored. Indeed, the discussions of the 1970s (see section 3) have also estranged a part of the mathematical community from history of mathematics, but both the fact that a technical knowledge is needed to write the history of mathematics and that an important number of mathematical institutes have supported historians to be part of their institutes have prevented that a communication gap would have established between groups. It is, however, an enduring struggle and effort to keep this line of communication open, and to be both tolerant and exacting enough to keep it going.

The history of computing today seems to be in a situation not completely unlike the one mathematics historiography was in the 1970s and 1980s. Some of the Practitioners of the field have become estranged from the history now being written, and the historians have adopted new methodologies, bringing in institutional, economic and social motives, that have put the technical details of the machinery (both hard- and software) and the scientific underpinnings and usages in the background. The computer then often appears as a blackbox that, supposedly, need not be understood to tell the story. ${ }^{63}$

On top of that, In the meantime, computing has pervaded much if not all technologies and communications of today and also has started to affect scientific practice. Also here, it mostly functions as a black box which, so we are told by the businesses selling us the technology, need not be understood or reflected upon in order to be used. It has become part of everyday experience though its actual contribution almost always remains hidden and notunderstood. The computer as an actual, specific machine interacting with both machines and human beings, or the computing practice as a usage have become eroded in meaning and in historical situatedness. Moreover, the diversification of the field has resulted not just in a broad range of highly-specialized methods and approaches, but also in a fragmentation of communities who are no longer able or willing to talk to each other. This lack of communications across the field is intensified by commercial and political interests which are, today, more impacting than the scientific on the development of the field. By consequence, we are in a situation whereby a (critical) reflection on the whole field is either considered impossible or, worse even, discouraged. What is required then is not a modernist framework whereby the diversity of approaches is replaced by one ultimate approach ${ }^{64}$ nor a postmodern one where the diversity per se is being celebrated, but an approach which opens up the communication lines and allows to reconnect rather than to unify or reduce.

It is perhaps here that lies a challenge for historians of computing who profess their work not just for the sake of their fellow historians. Indeed, if the history of computing develops towards an all-encompassing but fragmented field which hides from itself in its specializations and applications, then the real challenge for the historians might be to try and take distance from current developments. Instead, retracing histories, making them visible and transparent, is the kind of answer history of computing can contribute to debates today, not just to render understandable the current situation, but also to change it by making it

\footnotetext{
63 Of course, there are some exceptions. See for instance Priestley, 2011, Daylight, 2014 ; De Mol, Carlé and Bullynck, 2015.

64 See e.g. BourBaKI ,1950 for a classic case of modernist mathematics.
} 
historically responsible. 


\section{RÉFÉRENCES}

Aspray (William), 1994, “The History of Computing Within the History of Information Processing”, History and Technology, volume 11, p. 7-19.

Aspray (William), 2014, “Michael Sean Mahoney (1939-2008)”, IEEE Annals of the History of Computing, vol. 36, $\mathrm{n}^{\circ} .3$, p. 70-79,

Aspray (William), 2015, “The Many Histories of Information, Information \& Culture, volume $50 \mathrm{n}^{\circ} 1$, p. $1-23$

Bourbaki, Nicholas, 1950, "The architecture of mathematics", The American Mathematical Monthly, vol. 57, n 4, p. 221-232.

Bullynck (Maarten), 2016, “Histories of algorithms: Past, present and future.”, Historia Mathematica, vol. 43, n 3, p. 332-341.

Campbell-Kelly (Martin), Aspray (William), 1996, Computer: A history of the information machine, New York, Basic Books.

Campbell-Kelly (Martin), 1980, "Programming the EDSAC: Early Programming Activity at the University of Cambridg”, IEEE Annals of the History for Computing, vol. 2, n 1, p. 7-36.

Campbell-Kelly (Martin), 2007, “The history of the history of software”, IEEE Annals of the History for Computing, vol. 29, n 4, p. 40-51.

Campbell-Kelly (M.), 2013, “Remembering Michael Sean Mahoney”, Perspectives on Science, vol. 21, n 3, p. 379-383.

Ceruzzi (Paul E.), 1998, A History of Modern Computing, Cambridge (Mass.), MIT Press.

Chemla (Karine), 1987, “Should they read FORTRAN as if it were English?”, Bulletin of Chinese Studies, vol. 1, n 2, p. 301-316.

De Mol (Liesbeth), Carlé (Martin), Bullynck (Maarten), 2015, "Haskell before Haskell: an alternative lesson in practical logics of the ENIAC.”, Journal of logic and computation, vol. 25, $\mathrm{n}^{\circ}$ 4, p. 1011-1046.

Daylight, (Edgar G.), 2014, The dawn of software engineering,: from Turing to Dijsktra, Geel, Lonely Scholar Scientific Books.

Denning (Peter), 2009, “The profession of IT. Computing’s paradigm”, Communications of the ACM, vol. 52, n 12 , p. 28-30.

Eames (Charles), Eames (Ray), 1973, A Computer Perspective, Cambridge (Mass.), Harvard University Press.

Edwards (Paul N.), 2010, A Vast Machine. Computer Models, Climate Data, and the Politics of Global Warming, Cambridge (Mass.), MIT Press.

Forman (Paul), 2007, “The Primacy of Science in Modernity, of Technology in Postmodernity, and of Ideology in the History of Technology”, History and Technology, vol. 23, n 1, p. 1152. 
Goldstine (Herman H.), 1972, The Computer from Pascal to von Neuman, Princeton: Princeton University Press.

Haigh (Thomas), 2004, "The History of Computing: An Introduction for the Computer Scientist” , in Using History To Teach Computer Science and Related Disciplines, Akera (Atsushi), Aspray (William.)(eds.), Computing Research Association, Washington, p. 5-26.

Haigh (Thomas), 2011a, "The History of Information Technology," Annual Review of Information Science and Technology, $n^{\circ}$. 45, p. 431-487.

Haigh (Thomas), 2011b, "Unexpected connections, powerful precedents, and big questions : the work of Sean Michael Mahoney on the history of computing" in The Histories of Computing, Mahoney (Michael S.), Cambridge, Harvard University Press, p. 1-18.

Haigh (Thomas), 2015, “The tears of Donald Knuth”, Communications of the ACM, vol. 58, $\mathrm{n}^{\circ} 1$, p. $40-44$.

Hamming (Richard W.), 1980, "We would know what they thought when they did it", in A History of Computing in the Twentieth Century, Metropolis (Nicholas), Howlett (Jack), Rota (Gian Carlo)(eds.), New York, Academic Press, p. 3-9.

ITARD (Jean), 1974, “A propos d'un livre sur Pierre Fermat”, Revue d'histoire des sciences, t. $27, \mathrm{n}^{\circ} 4$, p. 335-346.

Knuth (Donald E.), 1972, “Ancient Babylonian algorithms”, Communications of the ACM, vol. 15, n 7, p. 671-677.

Knuth (Donald E.), Pardo, (Luis T.), 1976, “The Early Development of Programming Languages”, Stanford University, Computer Science Dept., Report STAN-CS-76-562, August.

KNUTH (Donald E.), 2014, "Let's not dumb down the history of computer science , Kailath lecture by Knuth”, Wednesday, May 7, 2014, Stanford University, http://kailathlecture.stanford.edu/2014KailathLecture.html.

Koblitz (Neil), 2008, Random Curves: Journeys of a Mathematician, Berlin, Springer.

Lee (J. A. N.), 1996, “Those who forget the lessons of history are doomed to repeat it or, Why I study the history of computing”, IEEE Annals for the History of Computing, vol. $18, \mathrm{n}^{\circ} 2$, p. 54-62.

Mahoney (Michael S.), 1971, "Die Anfänge der algebraischen Denkweise im 17. Jahrhundert”, Rete: Strukturgeschichte der Naturwissenschaften , vol 1, p. 15-31.

Mahoney (Michael S.), 1988, "The History of Computing in the History of Technology”, IEEE Annals of the History of Computing, vol. 10, n² 2, p. 113-125

Mahoney (Michael S.), 1996, “What makes history?”, in History of Programming LangagesII, Bergin (Thomas J), Gibson (Richard G.), New York, ACM Press, p. 831-832.

Mahoney (Michael S.), 2011, The Histories of Computing, ed. with an introduction by Thomas Haigh, Cambridge (Mass.), Harvard University Press.

MAY (Kenneth O.), 1974, "Should we be mathematicians, historians of science, historians, or generalists”, Historia Mathematica, vol. 1, n² 2, p. 127-128. 
MaY (Kenneth O.), 1980, " Historiography: A perspective for computer scientists", in A History of Computing in the Twentieth Century, Metropolis (Nicholas), Howlett (Jack), Rota (Gian Carlo)(eds.), New York, Academic Press, p. 11-18.

Metropolis (Nicholas), Rota, (Gian-Carlo), 1980, "Preface” in A History of Computing in the Twentieth Century, Metropolis (Nicholas), Howlett (Jack), Rota (Gian Carlo)(eds.), New York, Academic Press, p.xv-xvii.

Metropolis, (Nicholas), Howlett, (Jack), Rota, (Gian-Carlo)(eds.,), 1980, A History of Computing in the Twentieth Century, New York, Academic Press.

November (Joseph), 2012, Biomedical Computing: Digitizing Life in the United States, Baltimore, Johns Hopkins University Press.

Priestley (Mark), 2011, A science of operations. Machines, logic and the invention of programs, Springer.

Randell (Brian) (ed.), 1973, The Origins of Digital Computers. Selected Papers, Berlin/Heidelberg/New York, Springer Verlag.

Rosin (Robert. F.), 1996, "Forum on the history of computing”, in History of Programming Languages. II, Bergin (Thomas. J), Gibson (Richard G.) (eds.), New York, ACM Press, p. 772-830.

Rowe (David), 2016, “Otto Neugebauer's vision for rewriting the history of ancient mathematics", in Historiography of Mathematics in the 19th and 20th centuries, Remmert (Volker), Schneider (Martina), Sörensen (Henrik Kragh)(eds.), Basel, Birkhäuser, p. 123-141.

SARTON (George), 1924, “The new humanism”, Isis, vol. 6, n 1, p. 9-42.

Sarton (George), 1936, The Study of the History of Mathematics, Cambridge (MA), Harvard University Press.

SCHNEIDER (Martina), 2016, “Contextualizing Unguru's 1975 attack on the historiography of ancient greek mathematics", in Historiography of Mathematics in the 19th and 20th centuries, Remmert (Volker), Schneider (Martina), Sörensen (Henrik Kragh)(eds.), Basel, Birkhäuser, p. 245-267

Staudenmaier (John M.), 1990, “Comment. Recent trends in the history of technology”, The American Historical Review, vol. 95, n³, p. 715-725.

Tedre (Matti), 2015, The Science of Computing: Shaping a Discipline, Boca Raton, CRC Press.

Tropp (Harry S.), 1980, "The Smithsonian Computer History Project and some personal recollections", in A History of Computing in the Twentieth Century, Metropolis (Nicholas), Howlett (Jack), Rota (Gian Carlo)(eds.), New York, Academic Press, p. 115-122. Historiography of Mathematics in the 19th and 20th centuries, Remmert (Volker), Schneider (Martina), Sörensen (Henrik Kragh)(eds.), Basel, Birkhäuser, p. 115-122.

Weil (André), 1973, “Review: M. S. Mahoney, The mathematical career of Pierre de Fermat”, Bulletin of the American Mathematical Society, vol. 79, n 6, p. 1138-1149,

WeXelblat (Richard L.) (ed.), 1981, History of Programming Languages, New York, ACM 
Press. 